\title{
Immersive Learning Environment Using 3D Virtual Worlds and Integrated Remote Experi- mentation
}

\author{
http://dx.doi.org/10.3991/ijoe.v9iS1.2353
}

\author{
R. Marcelino ${ }^{1}$, Silva J.B. ${ }^{1}$, V. Gruber ${ }^{2}$, Bilessimo, M.S. ${ }^{1}$ \\ ${ }^{1}$ Universidade Federal de Santa Catarina (UFSC), Araranguá, Brazil \\ 2 Universidade Federal de Santa Catarina (UFSC), Criciúma, Brazil
}

\begin{abstract}
This project seeks to demonstrate the use of remote experimentation and $3 D$ virtual environments applied to the teaching-learning in the areas of exact sciences-physics. In proposing the combination of remote experimentation and $3 \mathrm{D}$ virtual worlds in teaching-learning process, we intend to achieve greater geographic coverage, contributing to the construction of new methodologies of teaching support, speed of access and foremost motivation for students to continue in scientific study of the technology areas. The proposed architecture is based on a model implemented fully featured open source and open hardware. The virtual world was built in OpenSim software and integrated it a remote physics experiment called "electrical panel". Accessing the virtual world the user has total control of the experiment within the $3 \mathrm{D}$ virtual world.
\end{abstract}

Index terms - 3D virtual worlds, Remote Experimentation, Open Source, Open Hardware.

\section{INTRODUCTION}

This project seeks to contribute resources to meet the need to make experiments and to encourage students to follow careers in scientific and technological collaboration with the social integration of science and technology. Currently educational methods have been changing. Students have found it difficult to adapt to the traditional teaching techniques still used in the classroom. New methods of teaching, called desirable methods, are alternatives that have appeared and showed to be necessary for this new generation of "plugged-in people " [1]. Remote Experimentation Laboratories (REXLAB) seek help with tools that can promote improvements in teaching methods, modernizing teaching and approach concepts in practical activities. Through access to remote experiments via the 3D virtual world RExLab provides interactivity with a scientific and technological environment for users. This environment is characterized by reality, space requirements and devices, similar to the laboratories "hans-on", however, distinguished by geographical separation. The remote experimentation appears as an extremely interesting alternative to the limited availability of university laboratories, since it can be accessed at any time and is connected to the worldwide computer network available 24 hours a day, 7 days a week. Due to its access availability, it becomes easy for the user to interact with the virtual practical activity.[2]

\section{REMOTE LABORATORY}

Conducting experimental activities in a well-equipped laboratory is universally regarded as an essential skill to understand science \& engineering theories and concepts. However, it is also widely recognized that not all science \& engineering students have access to the same laboratory conditions, i.e. to the same type, quantity and diversity of laboratory instruments/apparatus. In many institutions, this lack of resources (in many cases caused by the number of students enrolled in a particular course) is addressed by two simple solutions [3]: the teacher conducts a series of demonstrations in the laboratory (requires less equipment) or the students are invited to conduct a series of simulations (requires no equipment, except for a simple PC equipped with the right software). In a number of situations, the teacher may choose to demonstrate a given theory or concept by conducting a remote experiment, either in the laboratory or in a normal classroom, by simply using a PC connected to the Internet and a video projector. Using the PC web browser the teacher accesses a remote laboratory and conducts a given experiment, thus demonstrating to the entire class the addressed physical/theoretical concept.

Related literature refers three different laboratory environments used in a teaching/learning process: (i) presential (hands-on) laboratories; (ii) remote laboratories; and (iii) virtual laboratories. A remote laboratory allows a remote client to actually control/observe a given experimental equipment/apparatus through a simple web browser [3]. A virtual laboratory allows the same actions and the same access mechanism, with the difference that the experimental equipment/apparatus is replaced by a computer model [4]. In sum, these two laboratory environments share the same principle, i.e. the use of ICT for facilitating the acquisition of laboratory competences by students with reduced or no access at all to convenient experimental equipment/apparatus.

From these facts, it seems acceptable that ICT can be used, in an effective manner, in a teaching/learning process. Our envisaged learning environment seeks to explore the resources presented by Internet-based laboratories (both remote and virtual), by following a reasoning principle that learning in itself, as a mental activity, is not committed to the classic (presential) classroom but can happen in any place and at any time a person is seeking for understanding/knowledge. In addition, the remote and 
simulated experiments contribute to cost savings and to the solving of time/space restrictions associated with real laboratories.

\section{USING VIRTUAL WORLDS AS IMMERSIVE LEARNING ENVIRONMENTS}

Three aspects have been contributing to an unprecedented communication and connectivity degree among citizens, at a global scale: (i) the increased (and everyday increasing) processing power of simple PCs, (ii) the increased (and increasing) bandwidth in residential communication networks, accessible to the general public, and (iii) the widespread use of the Internet and associated technologies. Some of these aspects have also enabled the implementation of distributed virtual environments, supporting collaborative mechanisms, on more or less affordable computational platforms. A collaborative virtual environment is a simulated world gathering geographically dispersed users, all connected through the Internet. Although geographically apart, all users share a common view of that world, which allow them to not only communicate but also collaborate and interact [5].

Virtual worlds can be regarded as virtual learning environments (a computational metaphor of a real learning environment) comprehending persons, locations, and objects basically allowing some form of interaction. Available functionalities, such as the existence of avatars, allow users to feel as part of the virtual world, thus creating a sense of "immersion". Virtual worlds can be used at different educational levels, like formal education, language teaching, and training of social skills, or even used for simple virtual meetings or gatherings. This sense of immersion is felt to be crucial for the effective conduction of remote experiments. Virtual worlds are in fact rich environments for providing a sense of immersion since they offer 3D representations, visual perspectives from each avatar, and interaction mechanisms.

This context facilitates the acquisition of knowledge and skills, providing that students are allowed to interact with the reality itself and from that interaction and the results provided by the real instruments and experimental apparatus infer valid scientific conclusions related to the observed phenomena. This approach allows students to actively participate in the search for knowledge, in a constructivist perspective [6]. Providing access to a remote laboratory, from a virtual world, thus allows:

- Students to experience a sense of immersion on the provided learning environment;

- Creating "bonds" between student(s) and teacher(s);

- Increasing students’ motivation;

- Navigating in the virtual world in any direction;

- Conducting real experiments;

- Interacting with objects of the virtual world, like moving things and opening doors, etc.;

- Doing the proposed activities according to the student own working rhythm or pattern;

- No time restrictions, i.e. students having to stop the experiment because the class is over.

Unlike currently available e-learning platforms or LMS - which support didactical contents in many different formats and media types, e.g. video, audio, animations, simulations, while also presenting an whole range of applications, e.g. chats, discussions forums, quizzes, among others - virtual worlds allow schools, universities and training centres to create a learning environment closely matching that of a real classroom or laboratory, i.e. with persons (teachers/students), a blackboard, a screen for presenting slides, tables and/or workbenches, chairs, equipment, etc., while also allowing for the support of basic behaviour rules. This clearly works against a cause of drop backs in science and engineering courses, i.e. a pure traditional educational process, which fails to observe or accommodate the expectations of natives born in the new digital era.

Virtual worlds are also a promising environment, regarding this particular aspect, as they allow for (i) an augmented interaction among users and (ii) extended manipulation possibilities with the virtual objects present in a given world. Migrating from an environment where interactions occur mainly through text or diagrams into an environment that emulates the physical world and where interactions occur almost seamlessly from the user movements (like raising a - virtual - hand or moving forward), provides an increased sense of immersion, to both teachers and students, which is regarded as a crucial factor to guarantee the success of remote labs. For instance, Kemp and Livingstone [7] state that compared to other electronic tools, environments such as OpenSimulator and Second Life may provide an increased "sense of location" (i.e. feeling as being there).

A laboratory for educational purposes should also be seen as a "community of learning", favouring all sorts of interactions between teachers and students, and among students themselves, in particular. Students are motivated to collaborate if they understand well their role and the partners' role, and also the benefits resulting from that collaboration.

\section{THE REXLAB VIRTUAL WORLD}

The proposed learning environment is based on a 3D virtual environment, accessible via Web, that allows students to feel as being in a traditional classroom, interacting with a teacher and other students, for building knowledge on a particular topic. Students can also collaboratively conduct remote experiments from within this $3 \mathrm{D}$ virtual world, to practice the theory and concepts learnt.

Figure 1 illustrates the proposed 3D virtual world, running on a simple PC, comprehending several software packages (a database, Moodle, Sloodle, and OpenSim) and the link to the remote experiment, supported by MicroWeb Servers (MWS). The proposed environment also aims to dissipate a general (wrong) feeling among youngsters that science and engineering are complicated, unappealing study matters.

The implemented model uses the resources of the open source Learning Management System Moodle and open hardware platform Arduino and Microserver (developed in the laboratory). It also has a virtual $3 \mathrm{D}$ environment with access to real experiments that utilizes the SLOODLE (mashup of Moodle with Second Life) and the OpenSim virtual world server. Figure 02 shows the system architecture.

The material published in Moodle is available in the 3D virtual environment where students and teachers can use it in a digitized environment that simulates a classroom. 


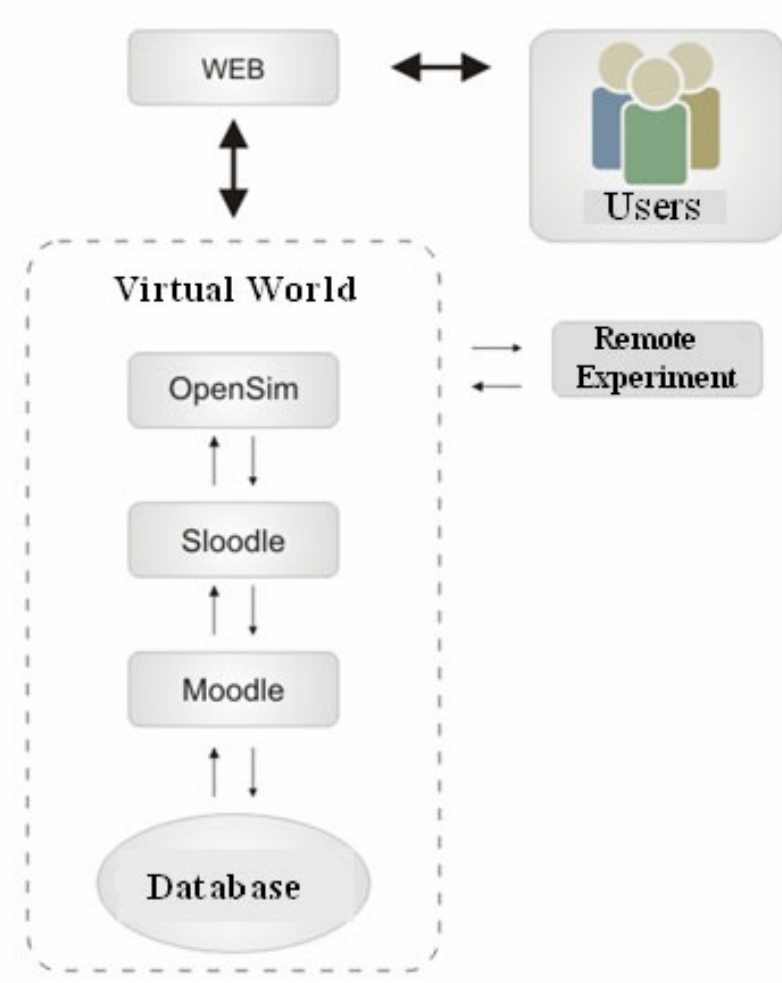

Figure 1. Proposed architecture

Interacting on page available on the Internet developed in PHP and using JavaScript for the interface. Data are sent to the WEB Microserver addressed by IP. Interconnected with the experiments these codes are driven by .Cgi stored in the microcontroller. An IP camera is used to see the experiment in action.

These features open source and the integration of hardware with virtual worlds innovate scientific reality for educational purposes, allowing the implementation of the software without a license acquisition costs. With custom avatars, chatting, eye contact, digitized and interactive environments, students, teachers and even other partner institutions can share knowledge by simulating a real sense of presence and a high degree of immersion.

The system is multiplatform, allows users of different operating systems like Linux, Windows and Mac OS, can access the Remote Laboratory Experimentation through 3D Virtual Environment, interacting with real experiments and visualizing the results. Figure 3 shows the virtual world and experiment with remote avatars.

\section{CONCLUSIONS AND FINAL CONSIDERATIONS}

Virtual environments and remote experimentation are presented as appropriate tools for the teaching-learning collaborative process, they offer an interesting perspective for teaching collaborative and distributed across multiple applications. These are technologies that can promote a high degree of immersion, providing a feeling of real presence and interaction.

In the exhibition the work aims to show the integration between virtual worlds and 3D remote experiments, allowing more attractiveness to students who are studying the fundamental concepts of science and technology careers.

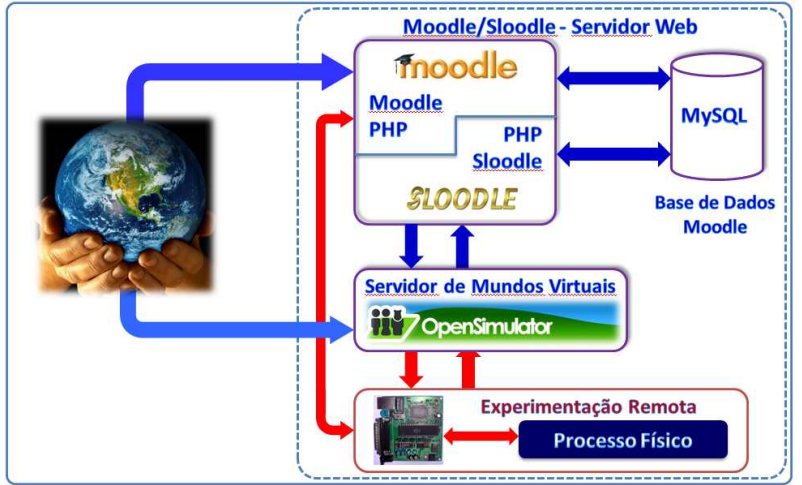

Figure 2. Interaction between $3 \mathrm{D}$ virtual world and remote experiment

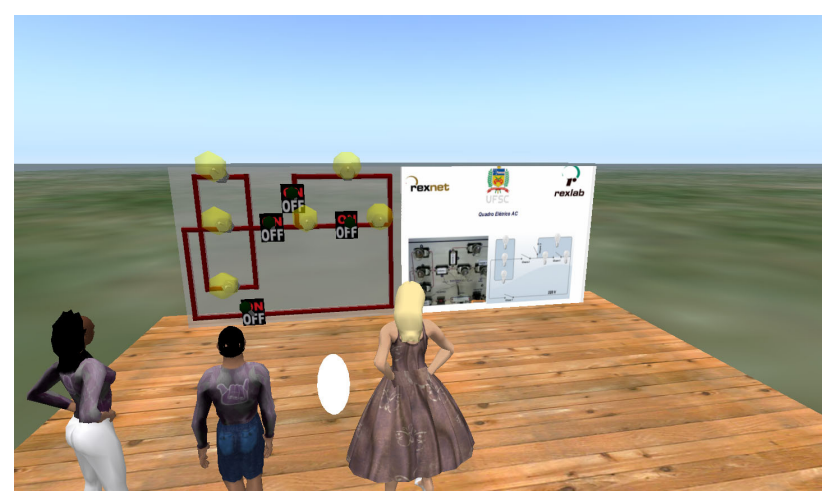

Figure 3. Interaction between $3 \mathrm{D}$ virtual world and remote experiment

The work described in this paper was partially motivated by the educational potentialities offered by the new ICT, namely the access to information, its interactive manipulation, and the possibility to derive new knowledge and skills from that very same interactive process. The full exploration of these new potentialities implies new educational strategies, new didactical approaches and also new pedagogical theories. Furthermore, the social competences and skills acquired during the utilization of these 3D virtual learning environments can be an added value if later used in a personal and/or professional perspective. Again, the ancient principle that schools prepare students for life is also applicable to the use of $3 \mathrm{D}$ virtual worlds in an educational perspective.

It should be emphasized that many teachers, nowadays, feel attracted by the number and potentialities of currently available educational technologies/resources and have actually been using them to exercise their teaching role, while addressing a students' reflexive learning perspective. These teachers seek to provide students with new skills and competences they think to be essential in a global communicating world, where the use of social networks is part of the daily life, not only in a person's private life but also in many professional aspects, especially in corporations operating worldwide.

Several students have already accessed the provided 3D virtual world on a pure experimental basis, and have reported a genuine interest and curiosity with the new learning environment. The major strength seems to reside on the level of interaction provided by the learning environment, namely by the possibility to have an avatar navigating through the virtual world. 


\section{REFERENCES}

[1] MARCELINO, R. ; Silva, Juarez Bento da ; Alves, Gustavo Ribeiro ; Shaeffer, Lírio . Extended Immersive Learning Environment: A Hybrid Remote/Virtual Laboratory. International journal of online engineering(iJOE), v. 6, p. 1-6, 2010

[2] Silva, Juarez B. ; Gruber, Vilson ; Marcelino, Roderval . New Technologies for Information and Communication, PWM Remote Experimenting and 3G Networks as Teaching Support. International Journal of Engineering Pedagogy (iJEP), v. 2, p. 17-22, 2012.

[3] Alves, G. R.; Ferreira, J. M.; Müller, D.; Herbe, H.; Hine. N. ; Alves, J. B. M.; Pereita, C. E.; Chiang, L.; Herrera, O; and Sucar, E. Remote Experimentation Network - Yielding an InterUniversity Peer-to-Peer e-Service. In: International Conference on Emerging Technologies and Factory Automation (ETFA), Catania, Italy, 2005.

[4] Corter, J. E.; Nickerson, J. V.; Esche, S. K., Hassapis, C ; IM S., MA, J. Constructing reality: a study of remote, hands-on, and simulated laboratories. ACM Transactions on Computer-Human Interaction. Vol 14, No 2, Aug. 2007.

[5] B. Rohel, "Distributed Virtual Reality - An Overview”, 1995.

[6] Kemp. J, Livingstone, D. - Putting a Second Life "metaverse" skin on leaning management systems (Sloodle whitepaper). [online] [Accessed 27/12/2007]. Available at: http://www.sloodle. com/whitepaper.pdf

\section{AUTHORS}

R. Marcelino, is a researcher at Universidade Federal de Santa Catarina (UFSC), Informatics, Araranguá, Brazil. (e-mail: roderval@yahoo.com.br).

J.B. Silva, is a researcher at Universidade Federal de Santa Catarina (UFSC), Informatics, Araranguá, Brazil. (e-mail: juarezbs@mail.com).

V. Gruber, is a researchetr at Universidade Federal de Santa Catarina (UFSC), Telecommunication, Araranguá, Brazil. (e-mail: vilsongruber@msn.com).

Bilessimo, M.S, is a researcher at Universidade Federal de Santa Catarina (UFSC), Production Engineering, Araranguá, Brazil. (simone.bilessimo@gmail.com).

This article is an extended and modified version of a paper presented at the International Conference on Remote Engineering \& Virtual Instrumentation (REV2012), held at University of Deusto, Bilbao, Spain, July 4-6, 2012. Received 14 November. Published as resubmitted by the authors 18 December 2012. 